\title{
Characteristic Production Decline Patterns for Shale Gas Wells in Barnett
}

\section{Keqiang Guo ${ }^{\text {a }}$, Baosheng Zhang ${ }^{\mathrm{a}^{*} \text {, }}$ Henrik Wachtmeister ${ }^{b}$, Kjell Aleklett ${ }^{b}$, Mikael Höök ${ }^{b}$}

${ }^{a}$ China University of Petroleum (Beijing), Fuxue Road 18, Changping, Beijing 102249, China

${ }^{b}$ Uppsala University, Villavägen 16, Uppsala 752 36, Sweden

Received: December 16, 2016/ Accepted: February 14, 2017

\section{Abstract}

This paper derives characteristic decline patterns for shale gas wells by analyzing historical well production data using decline curve analysis of 14,453 shale gas wells in the Barnett shale play from 2000 to 2014. The Hyperbolic model and the Stretched Exponential model are applied on the well-by-well production data at average aggregate well and individual well levels to derive the characteristic parameters. Both the Hyperbolic curve and the Stretched Exponential curve display a good fit to the data for both the average aggregate and the individual shale gas wells. The Hyperbolic model performs slightly better than the Stretched Exponential model in this study. The first year rate of decline for production of a shale gas well is around $60 \%$ and over the first two years is around $73 \%$. There is an increasing trend in initial production for new wells over the last decade. A supposed cut-off production rate of 133 $\mathrm{Mcf} / \mathrm{d}$ results in the estimated ultimate recoverable resource (URR) of about 1.4-2.7 billion cubic feet and a well life time of 11-29 years, which is in line with other studies.

Keywords: shale gas; decline curve analysis; Barnett

\begin{tabular}{l}
\hline Abbreviations: \\
\begin{tabular}{|lll|}
\hline URR & $:$ & Ultimate Recoverable Resource \\
SE & $:$ & the Stretched Exponential model \\
Mcf & $:$ & mille cubic feet \\
Mcf/d & $:$ & mille cubic feet per day \\
Bcf $\quad:$ & billion cubic feet \\
IP & $:$ & Initial Production \\
\hline
\end{tabular}
\end{tabular}

Corresponding Author

Tel.: +8601089733792 ; E-mail: bshshysh@cup.edu.cn

\section{Introduction}

In terms of pollutant emissions, natural gas is relatively cleaner than oil and coal and can partially replace them in some areas of consumption. Hence, it is more and more commonly believed that natural gas will be useful as a solution for improving sustainable development. While global conventional gas supply is facing increasing challenges in meeting demand, recent gas production has become increasingly reliant upon unconventional resources, such as hydrocarbons extracted from tight deposits, that cannot be produced at economic flow rates nor can they recover economic volumes unless special techniques are used to stimulate production. Such tight formations include tight sands, coal bed methane and gas-bearing shales. Shale gas accounts for the bulk of the recent increase in unconventional gas production and has become the focus of intense interest from business, policy makers and the wider public [1].

The surging hydrocarbon output witnessed over the last decade in the U.S. is commonly referred to as the "shale gas boom" or "shale revolution" [2]. Other countries have expressed hopes for developing such domestic unconventional gas resources, particularly shale gas, and are in various stages of planning and evaluation to lay the groundwork for potentially larger commercial undertakings in the future. This includes countries such as China [3], Poland [4], Mexico [5], India [6] and Australia [7]. However, the future development of unconventional gas resources still remains unclear as technological and economic factors remain uncertain [8]. In addition, there are studies that have also shown that the process of shale gas development may raise environmental concerns, such as water contamination, air pollution, earthquakes, nuisance and health concerns, and some other uncertain impacts.

Since the shale gas production has not been ongoing for very long, the data is still fairly limited. The "American experience" in the development of shale oil and gas is the most successful globally at present, and it has a relatively complete source of empirical data for shale gas production behavior, hence it serves as a suitable foundation for any attempt to describe or predict future shale gas production and its potential for global sustainable energy development.

\subsection{Shale gas in the United States}

Methodologies for analyzing production patterns have been around for many decades, and one of the most frequently used approaches is decline curve analysis [9]. Shale gas production is a fairly new activity and as a result the availability of long-term production data is still rather limited. To alleviate this, closer examination of the most prominent U.S. shale gas areas is needed. According to the EIA-Annual Energy Outlook 2015 [10], the production of total dry natural gas in the U.S. rose by $35 \%$ from 2005 to 
2013, with the natural gas share of the total U.S. energy consumption increasing from $23 \%$ to $28 \%$. In 2040 , the U.S. natural gas production from shale is predicted to account for about half of total domestic production.

Another EIA report [11] assessed 137 shale formations in 41 countries and claimed that shale formations are much more extensive than traditional gas reservoirs and are present on every continent. Technically recoverable shale gas resources were estimated at 7,201 trillion cubic feet (Tcf) for the entire world composing $32 \%$ of all global natural gas resources [11]. The U.S. and Canada are the only major producers of commercially viable natural gas from shale formations to date. However, about a dozen other countries have sunk exploratory test wells. China is the only nation outside of North America that has registered commercially viable production of shale gas, although the volumes contribute less than $1 \%$ of the total national natural gas production [12].

Shale resources and production are found in many regions of the U.S., but only seven areas are prolific. These are Marcellus, Haynesville, Eagle Ford, Fayetteville, Barnett, Woodford, and Bakken. Figure 1 illustrates the growth in natural gas output from different shale plays since 2000 . The Barnett shale, located in the Fort Worth Basin is one of the largest and the oldest onshore natural gas fields in the United States. It consists of sedimentary rocks and the productive part is estimated to cover about $13,000 \mathrm{~km}^{2}$ near the city of Dallas and at least 18 counties.

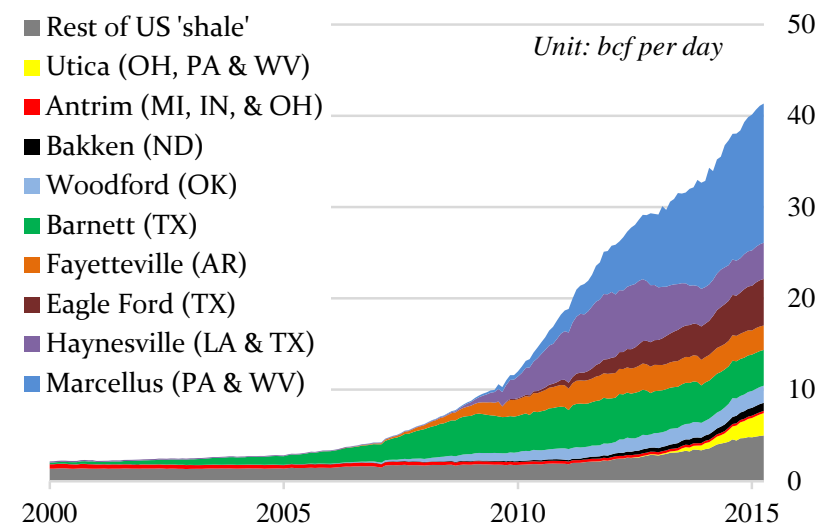

Figure 1 U.S. dry shale gas production by regions.

Data Source: EIA 2015 [10].

\subsection{Aim of this study}

Discovered in the 1950s, the Barnett formation was not commercially viable until the 1980 s, and significant drilling activity did not begin until gas prices increased in the late 1990s [13-14]. The Barnett shale play is sufficiently representative and of considerable analytic value because of its long production history and important position in the history of US shale developments (see green part in Figure 1). This study will focus on deriving representative production decline curves and analyzing their attendant decline rates, the initial production rate and the estimated ultimate recoverable resource (URR) for shale gas production by observing and modelling historical producing behavior of a number of shale gas wells in the Barnett play. Decline curve analysis models and statistical analysis will be applied on the well-by-well production data both on average aggregate well and individual well levels to find the distinctive parameters for shale gas production decline curves. Therefore, through the study of the shale gas production behavior in Barnett, increased understanding of issues surrounding production in shale formations in general can be acquired.

\section{Methodology and Data}

\subsection{Decline curve models}

Decline curve analysis is a method to analyze production rates of individual wells to predict the performance of future production by extrapolating a suitable decline function [15]. Many of the existing decline curve models are heuristic and based on a framework derived by Arps [16], who proposed that the curvature in the production-rate-versus-time curve can be expressed mathematically by the hyperbolic family of equations. In production decline curve models, the decline rate $(\lambda)$ can be expressed by using derivatives with production rate $(\mathrm{q})$ and time $(\mathrm{t})$ in arbitrary units [17], as shown in Eq. 1:

$$
\lambda=-\frac{d q / d t}{q}=C q^{\beta}
$$

Where $C$ is a constant and $\beta$ is the decline exponent constant. Three general cases exist: when $\beta=0$, the decline is exponential (Eq. 2); When $\beta=1$, the decline is harmonic (Eq. 3); When $0<\beta<1$, the decline is hyperbolic (Eq. 4).

$$
\begin{gathered}
q(t)=q_{0} e^{-\lambda\left(t-t_{0}\right)} \\
q(t)=q_{0}\left[1+\lambda\left(t-t_{0}\right)\right]^{-1} \\
q(t)=q_{0}\left[1+\lambda \beta\left(t-t_{0}\right)\right]^{-1 / \beta}
\end{gathered}
$$

Where $q(\mathrm{t})$ is the production rate, and $q_{\mathrm{o}}$ is an initial production rate at time $t_{\mathrm{o}}$ from which production begins to decline (i.e. its peak rate of production). Originally, the Arps curves were a set of mathematical equations with no physical basis other than that the equation gave a declining trend that provided a good fit with empirical data. However, a connection to physics has been proved for an exponential decline curve, which represents the solution to the flow equation at constant pressure [18]. This methodology has been widely used for forecasting production or estimating reserves in conventional oil and gas formations [19-23].

Due to particular reservoir conditions and seepage characteristics, production decline curves for shale gas wells differ from those of conventional gas reservoirs. It has been claimed that the Arps decline curves encounter problems when used in "unconventional" formations, particularly with regards to overestimation of reserves. When traditional 
decline curve models are used on shale formations, Arps' values for larger than 1 are commonly obtained yielding infinite cumulative production [24]. As the importance of shale gas has increased over the last decade new methods have been proposed to model the behavior exhibited by long horizontal wells with multistage hydraulic fractures in shale reservoirs. These methods include, but are not limited to, the Stretched Exponential (SE) model [25, 26], the Power Law model [24], and Duong's model [27].

Two decline curve analysis models are used in the study - the Arps Hyperbolic model and the Stretched Exponential model. The advantages of these decline curves lie in the strong empirical compliance they display and their ease of use. The down side of these analytical models is that they do not provide estimates of reserves or impart insight to reservoir characteristics. Their key properties are described in Table 1.

Table 1 Key properties of the Hyperbolic and the Stretched Exponential models. Adapted from Satter et al. [17], Valko [25, 26], Höök et al. [28], Kanfar [29] and Lei et al. [30].

\begin{tabular}{lll}
\hline $\begin{array}{l}\text { Key } \\
\text { properties }\end{array}$ & Hyperbolic & SE \\
\hline$q(\mathrm{t})$ & $q_{0}\left[1+\lambda \beta\left(t-t_{0}\right)\right]^{-1 / \beta}$ & $q_{i} \exp \left(-D_{i} t^{n}\right)$ \\
$Q(\mathrm{t})$ & $Q_{0}+\frac{q_{0}}{\lambda(1-\beta)}\left\{1-\left[1+\lambda \beta\left(t-t_{0}\right)^{1-\frac{1}{\beta}}\right]\right\}$ & $Q_{0}+\frac{q_{i} \tau}{n}\left\{\Gamma\left[\frac{1}{n}\right]-\Gamma\left[\frac{1}{n},\left(\frac{t}{\tau}\right)^{n}\right]\right\}$ \\
$U R R$ & $Q_{0}+\left[q_{0} / \lambda(1-\beta)\right]$ & $Q_{0}+\frac{q_{i} \tau}{n} \Gamma\left[\frac{1}{n}\right]$ \\
\hline
\end{tabular}

In Table $1, Q(\mathrm{t})$ is the cumulative production in the decline phase, $Q_{o}$ is the initial cumulative production, and URR is the estimated ultimate recoverable resource which is the sum of $Q_{o}$ and $Q(\mathrm{t})$ when $t \rightarrow t_{\text {cor }}$ (Figure 2). The cut-off rate $\left(q_{\text {cor }}\right)$ is the technical or economic limit of production, after which the well should be abandoned. For the Hyperbolic, modification of the parameter $\beta$ can alter the shape of the production rate curve and be used to determine what kind of decline curve is suitable for fitting to empirical data; the value of the decline parameter $\lambda$ governs how steep the decrease will be. In the SE method, $q_{\mathrm{i}}, D_{\mathrm{i}}$ and $n$ are undetermined parameters; a large $q_{\mathrm{i}}$ value compensates for a small $n$ value; $\tau$ is equivalent to $\left(n / D_{\mathrm{i}}\right)^{\wedge}(1 / n)[25]$.

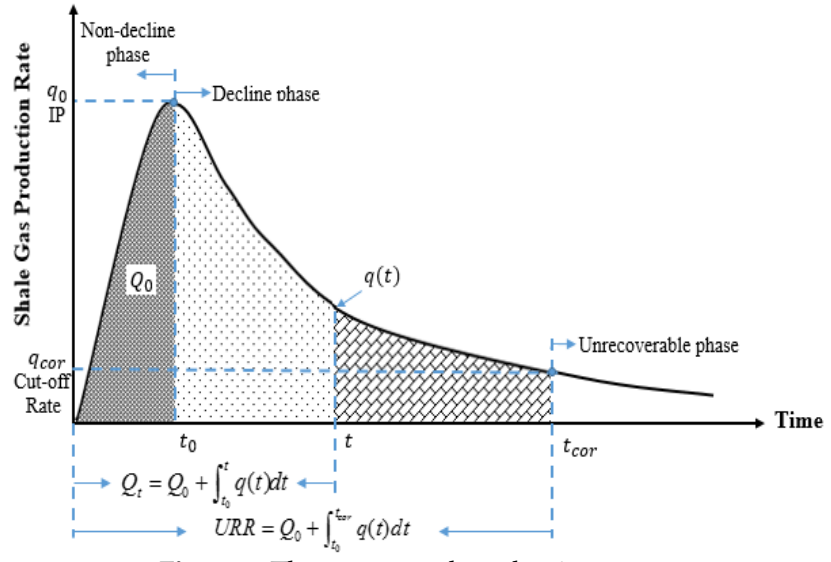

Figure 2 The conceptual production curve.

\subsection{Data handling}

The study is based on monthly shale gas production data from the DrillingInfo database that includes 14,453 shale gas wells from the Barnett shale play that commenced production in January 2000 with data culminating in October 2014 [31]. Only horizontal wells with separately reported production are included. Figure 3 shows the number of included wells by vintage. For production, the unit is thousand cubic feet (Mcf) as used in U.S. reported statistics. For conversion, 1 Mcf equals 28.32 cubic meters of natural gas.

The data set covers a maximum number of well production months of 174 (from April 2000 to October 2014). However, the decline phase does not typically cover the complete production time period. On average, for the shale gas wells investigated in this study, the initial cumulative production $\left(Q_{0}\right)$ accounts for about $7 \%$ of total well production, which means the decline curves capture most of the production. The production of a well usually peaks shortly after being brought on-stream and the decline curve describes the decline phase after the peak. Thus, the highest production before the onset of decline is denoted "Initial Production (IP)" by convention, as illustrated in Figure 2. In addition, months with zero production were removed before analysis, to remove external events that affected production such as annual maintenance and scheduled downtime. All of the other wells ' production data were completed by using this approach. 


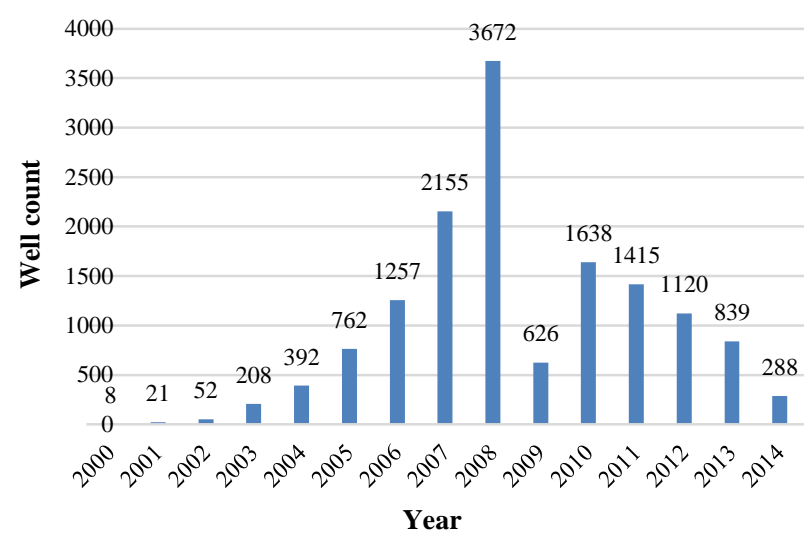

Figure 3 The original number of wells $(14,453$ in total)

The characteristic decline curves of shale gas wells were identified using several approaches. The first one is the normalized value approach that allows a broad set of wells to be directly compared. The production data are normalized in the sense that the initial production (IP in Figure 2) is set to 1 and the following monthly production figures are displayed as a fraction of this. Only the normalized decline curves can be obtained in this way, while actual production levels are lost through the normalization procedure. The actual value approach was also used to acquire production parameters such as the initial production and the estimated URR.

Characteristic decline curves can also be studied at either the average aggregate or individual well level. The "average aggregate decline curve" is fitted to the average monthly production of several wells, smoothing fluctuations and representing an average behavior for a collection of wells. A different number of wells are used for different months due to the limitation of the production data series. In contrast, the individual well decline curves are derived from analysis of the production of each individual shale gas well.

The number of observed data series should be long enough to avoid over-fitting. According to the characteristics of the shale industry and the data set, the period of two years (24 months) was set as the minimum number of production months. Therefore, only wells with production data exceeding 24 months are included during curve fitting.

\subsection{Goodness of fit}

Curve fits should be discarded unless they are capable of describing well behavior in a statistically acceptable way that agrees with actual data. This is referred to as the goodness of fit and can be measured in several ways. The coefficient of determination $\left(\mathrm{R}^{2}\right)$ and the normalized root mean square error (N-RMSE) are used as a measure for the goodness of fit to assess how well the models described the data in the curve fitting process.

$\mathrm{R}^{2}$ ranges from o to 1 , and the goodness of fit improves as $\mathrm{R}^{2}$ moves towards 1 ; for N-RMSE there is also ranges from o to 1 , but the goodness of fit weakens as it moves towards 1 . The boundaries that are introduced to exclude the poorest fits are $\mathrm{R}^{2} \geqslant 0.8$ and $\mathrm{N}-\mathrm{RMSE} \leqslant 0.2$ concurrently $[32,33]$. These limits may not be optimal or result exceptionally good fits, but the measure is primarily used to simplistically exclude appalling fits. The computer software, such as Matlab (Version R2014b), was used in the numerical analysis of the data set.

\section{Results}

\subsection{Decline curves}

\subsubsection{Average aggregate well decline curve}

About $84 \%$ (12,211 wells) of the original 14,453 wells have production data exceeding 24 months and these were normalized well by well. The aggregate normalized production of the first 10 years ( 120 months after IP) and the number of wells used for each month are displayed in Figure 4. The Hyperbolic and the Stretched Exponential models were fitted to the average aggregate normalized production data (the Red line in Figure 4).

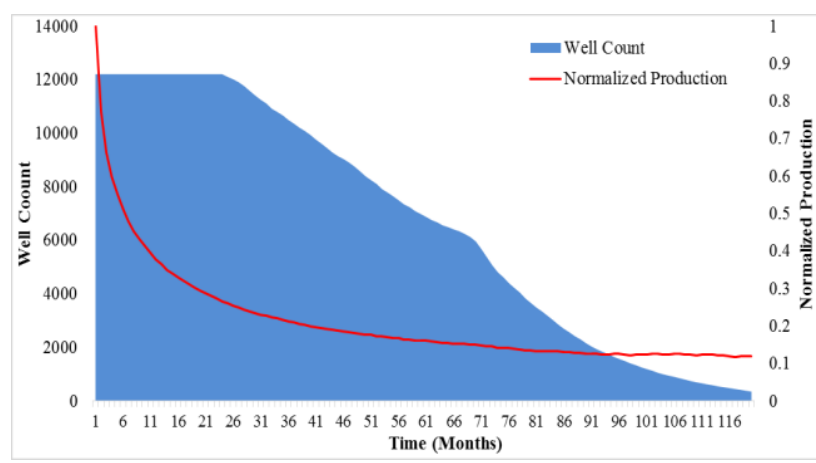

Figure 4 The average aggregate decline curve. Well number used for different months on the left $y$-axis and normalized production on the right $y$-axis.

The resulting curve fits are very similar and hard to distinguish on a regular scale, for this reason the curves are presented on a logarithmic scale, as shown in Figure 5. There is almost no difference between the models for $<50$ months. 


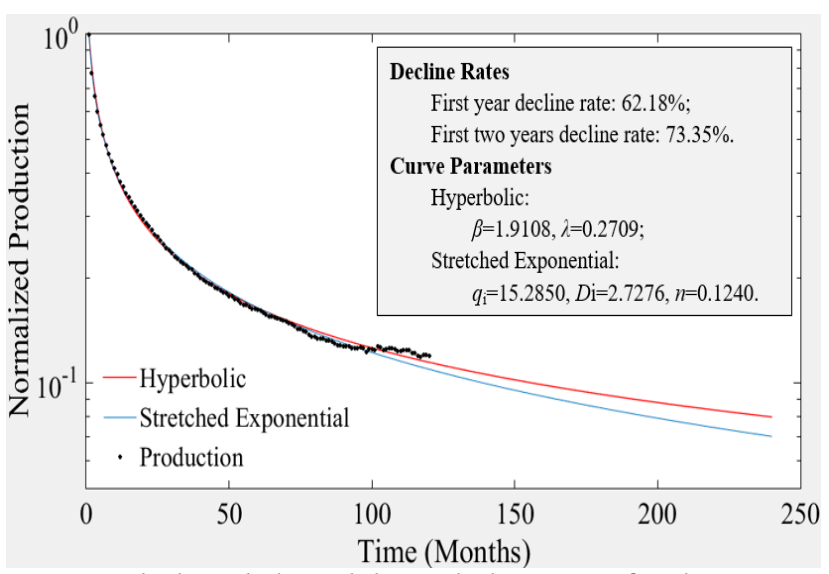

Figure 5 The hyperbolic and the SE decline curves fitted to average normalized production data on logarithmic scale

The decline rate slows down with increasing time. The annual decline over the first year of production is $62.18 \%$ and over the second year $29.53 \%$. Both curves are best fits with the goodness of fit in terms of R2 and N-RMSE. For the Hyperbolic model, the $\mathrm{R}^{2}$ value is 0.9982 , and the N-RMSE value is 0.0059; for and the Stretched Exponential model, the $\mathrm{R}^{2}$ value is 0.9988 , and the N-RMSE value is 0.0048 . The parameter values of the curves are also shown in the box in Figure 5 .

\subsubsection{Individual well decline curve}

Individual curve fitting using the Hyperbolic and the Stretched Exponential models was also performed on the 12,211 wells with data exceeding 24 months. After excluding poor fits based on the $\mathrm{R}^{2}$ and N-RMSE limits, a usable number of 8,547 wells remained. This is about $70 \%$ of 12,211 wells or $59 \%$ of the original 14,453 wells.

\section{(1) Hyperbolic decline curve}

The distributions for the best fitted $\lambda$ and $\beta$ parameter values of the hyperbolic fits are displayed in Figure 6 (a) and (b) respectively with key descriptive statistics attached in the textboxes. Some of the $\lambda$ values were extremely large $(>4,000)$, causing issues for visualization in histograms. Therefore, 16 wells with $\lambda$ values larger than 4 are excluded in Figure 6 (a).

In Figure 6 (b), the largest value for $\beta$ is 8.3; only about $16 \%(1,362$ of 8,547$)$ of the $\beta$ values are less than one; and values between 0.5 and 2.5 account for about $88 \%$ (7,556 of $8,547)$. Probability distributions of both parameters can be described by the Generalized Logistic distributions according to Chi-Squared tests (the Purple line, see Appendix A. 1 for details). The Normal distribution (the Red line, Appendix A. 2) are also displayed as comparison.

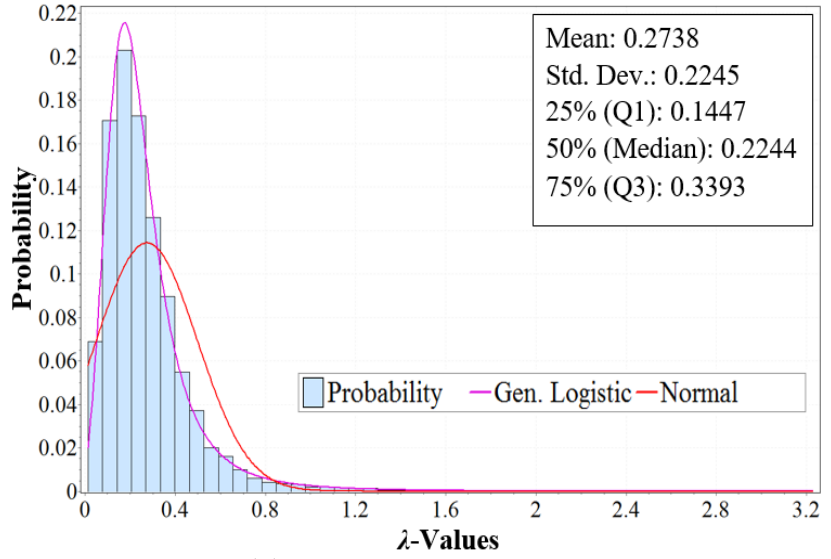

(a) Distributions of $\lambda$ values

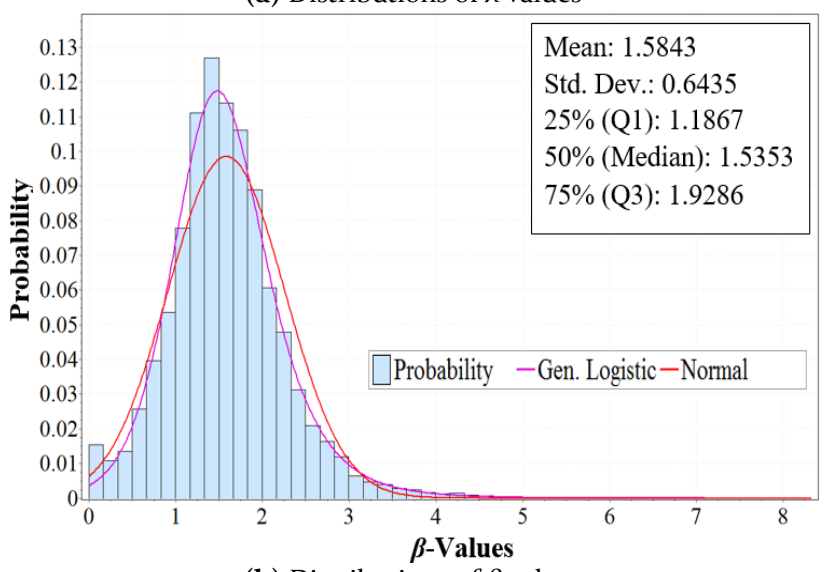

(b) Distributions of $\beta$ values

Figure 6 Distributions of Hyperbolic parameters

(2) Stretched Exponential decline curve

Some key descriptive statistics of the best fitted parameters for the Stretched Exponential decline curves are shown in Table 2.

Table 2 Descriptive statistics of the SE curves.

\begin{tabular}{lllll}
\hline & \multicolumn{1}{c}{$\boldsymbol{q}_{\mathrm{i}}$} & \multicolumn{1}{c}{$\boldsymbol{D}_{\mathrm{i}}$} & \multicolumn{1}{c}{$\boldsymbol{n}$} \\
\hline Mean & 186.8 & 2.3 & 0.3 \\
Std. Deviation & 625.2 & 2.3 & 0.3 \\
Min & 0.7 & $3.47 \mathrm{E}-7$ & 0.04 \\
25\%(Q1) & 1.8 & 0.6 & 0.1 \\
$50 \%($ Median) & 3.6 & 1.3 & 0.2 \\
$75 \%\left(Q_{3}\right)$ & 28.8 & 3.4 & 0.4 \\
Max & 7999.9 & 9.2 & 9.5 \\
\hline
\end{tabular}

\subsubsection{Comparison of decline curves}

Based on the studied historical production profiles, the characteristic decline curves for shale gas production are derived by using the Hyperbolic model and the Stretched Exponential model. Both the Hyperbolic model and the Stretched Exponential model fit well to the aggregate and the individual shale gas wells. Comparison by means of goodness of fit indicate that Hyperbolic curves are better fit than the Stretched Exponential for about 51\% (4,366 of 
8,547 ) of the wells according to the $\mathrm{R}^{2}$ and for about $61 \%$ $(5,198$ of 8,547$)$ of the wells according to the N-RMSE.

Figure 7 provides a summary of the different derived characteristic decline curves investigated in this study, including curves resulting from the median and mean of the estimated parameters for the Hyperbolic model and the median of the estimated parameters for the Stretched Exponential model. The three estimated parameters of the Stretched Exponential model are interconnected and by taking the mean, the connection between the parameters will be lost. In Figure 7, the average aggregate decline curves (see Figure 5) are also displayed. The average aggregate curves (the Purple solid line and the Purple dotted line) for two models are declining more gradually than their corresponding mean, median or mean lines. The Stretched Exponential median curve (the Green dotted line) are declining steepest over a medium to a long-term horizon while the hyperbolic median and mean curves (the Green solid line and the Red solid line) decline rapidly in the initial phase after which they flatten out.

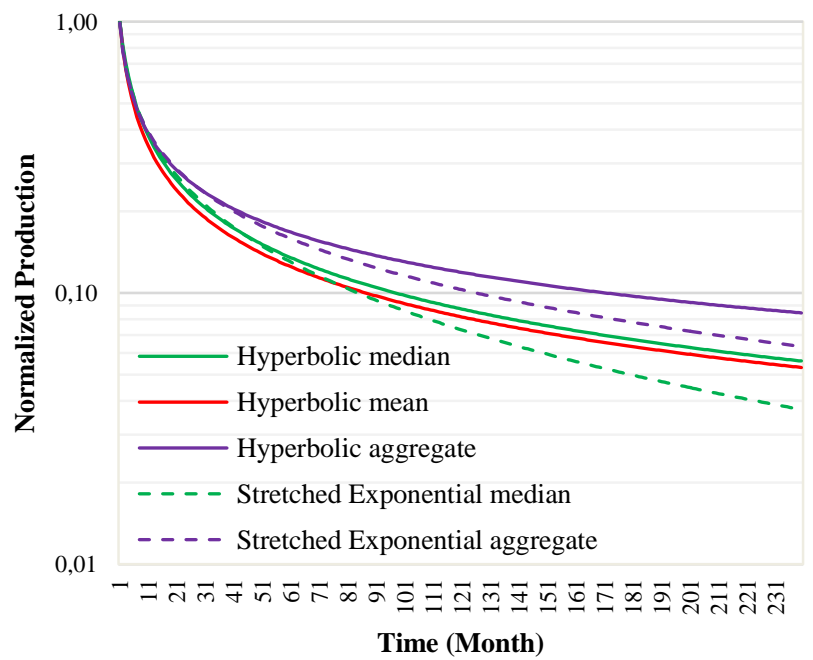

Figure 7 Summary of different derived typical decline curves. (on logarithmic scale)

\subsection{Decline rates and initial production}

The average decline rates in different time phases and the initial production, i.e. peak production, are also statistically analyzed based on the 12,211 wells.

\subsubsection{Comparison of decline curves}

The distributions for the first year (12 months after IP) decline rates and the decline rates over the first two years (24 months after IP) of every studied shale gas wells are displayed in Figure 8 (a) and (b) respectively.

The average value of the first year decline rates for all wells started in $2000-2012$ is $62.2 \%$ and the first two years decline rates is $73.4 \%$ (Table 3 ). The Generalized Logistic probability density function and the Normal distribution are listed in Appendix (A. 1 and A. 2).

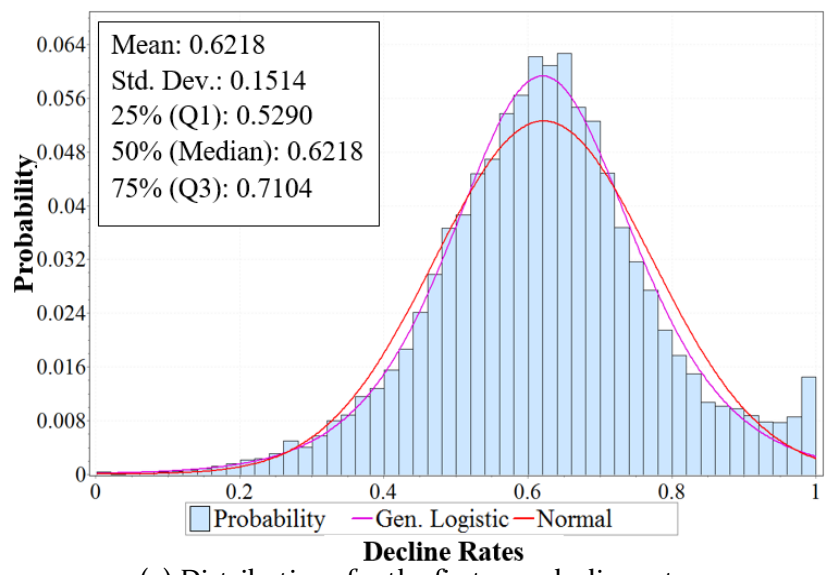

(a) Distributions for the first year decline rates

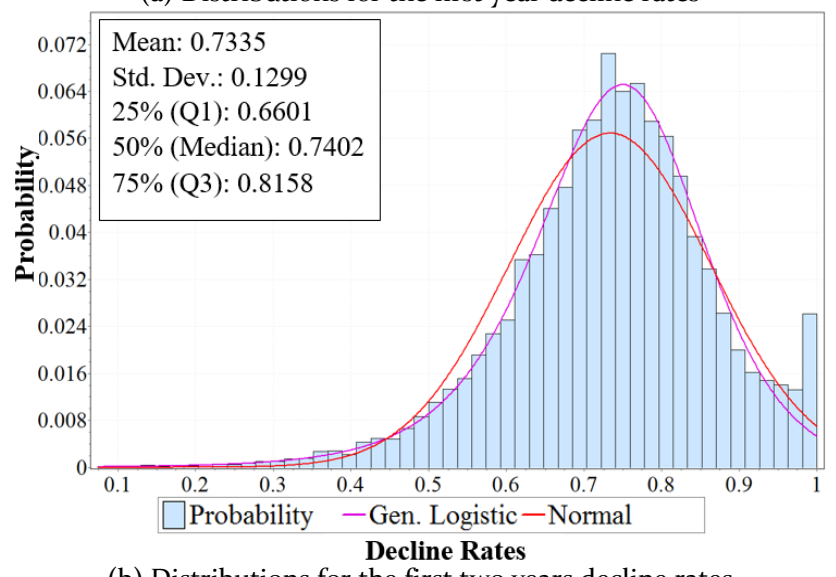

(b) Distributions for the first two years decline rates

Figure 8 Distributions for decline rates

Table 3 Average value of the first year and the first two years decline rates for new wells over years.

\begin{tabular}{lll}
\hline Year & First year & First two years \\
\hline 2000 & $56.3 \%$ & $75.2 \%$ \\
2001 & $54.0 \%$ & $66.9 \%$ \\
2002 & $60.5 \%$ & $68.8 \%$ \\
2003 & $58.1 \%$ & $69.3 \%$ \\
2004 & $59.5 \%$ & $70.3 \%$ \\
2005 & $61.9 \%$ & $73.1 \%$ \\
2006 & $64.5 \%$ & $76.1 \%$ \\
2007 & $64.2 \%$ & $73.9 \%$ \\
2008 & $62.0 \%$ & $73.6 \%$ \\
2009 & $63.3 \%$ & $75.2 \%$ \\
2010 & $62.4 \%$ & $73.9 \%$ \\
2011 & $61.3 \%$ & $72.8 \%$ \\
2012 & $57.6 \%$ & $69.1 \%$ \\
Total & $62.2 \%$ & $73.4 \%$ \\
\hline
\end{tabular}

The decline rate of production is around $60 \%$ for the first year and after two years only $27 \%$ of the initial production level remains due to production decline (Figure 8 (a), (b) and Table 3). These high decline rates are important, as they necessitate a significant number of new 
wells being drilled annually just to offset the decline in existing production. The results also verify the high decline rates for shale wells found by other researchers. In comparison, they are significantly higher than the average decline rates seen for conventional petroleum.

\subsubsection{Initial production}

The IP distribution from all wells that commenced production in 2000-2012 are displayed in Figure 9 (a). About $77 \%(9,367$ of 12,211$)$ of wells reach a peak monthlyproduction in the interval from 20,000 to 100,000 Mcf, which is about 658-3,290 Mcf/d. Figure 9 (b) shows average IP for wells by age. There is a clear trend towards higher IP levels. That is to say, newer wells tend to have higher IP than the older wells. This could be explained by technological developments such as the increased horizontal lengths of wells and the increased number of fracturing stages. The Log-Pearson 3 probability density function and the Normal distribution are listed in Appendix (A. 3 and A. 2).

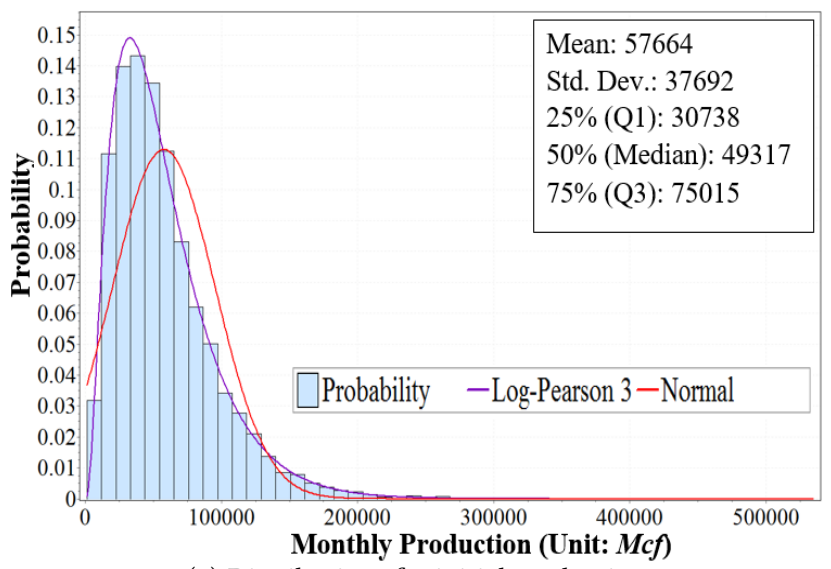

(a) Distributions for initial production

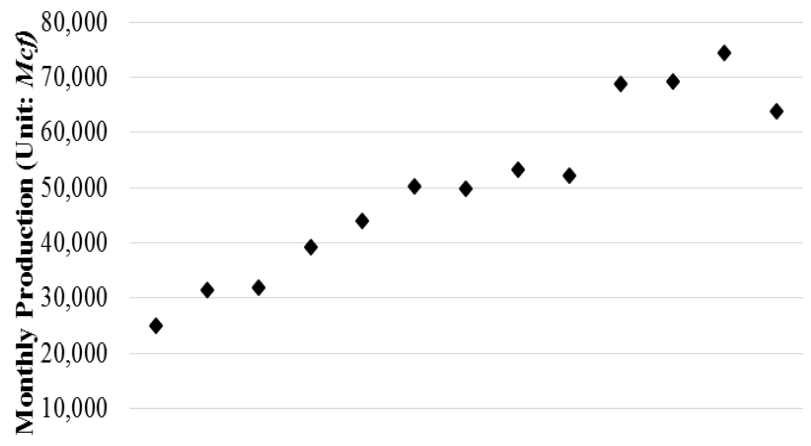

0

2000200120022003200420052006200720082009201020112012 Time (Year)

(b) Average monthly IP from 2000 to 2012.

Figure 9 Distributions for IP and Average monthly IP

\subsection{Estimated URR}

For the studied shale gas wells, the mean cumulative production before the peak (IP) is 60.5 Mcf, which is regarded as $Q_{0}$ in the $Q(t)$ functions shown in Table 1. This is just a few percent $(<7 \%)$ of the ultimate production and rather insignificant compared to the production output in the decline phase. The URR will be chiefly dependent upon the length of the decline phase and the IP.

The IP mean value of 1,896 Mcf/d (Figure $9(\mathrm{a})$ ) and characteristic decline curves from Figure 7 can be used, with assumptions on well life span, to estimate cumulative production. Results for assumed life times of 10-year, 20year, 30-year and 40-year are displayed in Table 4. Due to the high decline rates, production levels would be very low 10 years after the peak and could be below the economic limit. Hence, assumptions of very long life spans (>20 years) for shale wells must be properly grounded.

Table 4 The expected cumulative production per well. Unit for $\mathrm{q}(\mathrm{t})$ is $\mathrm{Mcf} / \mathrm{d}$ and for $\mathrm{Q}(\mathrm{t})$ is billion cubic feet (Bcf).

\begin{tabular}{|c|c|c|c|c|c|c|}
\hline \multicolumn{3}{|c|}{ Model } & \multirow{2}{*}{$\frac{\text { 10-year }}{166}$} & \multirow{2}{*}{$\begin{array}{l}\text { 20-year } \\
106\end{array}$} & \multirow{2}{*}{$\begin{array}{l}\text { 30-year } \\
82\end{array}$} & \multirow{2}{*}{$\frac{40-\text { year }}{68}$} \\
\hline \multirow{6}{*}{$\mathrm{H}$} & Median & $q(t)$ & & & & \\
\hline & Mean & $\mathrm{Q}(\mathrm{t})$ & 1.4 & 1.9 & 2.2 & 2.5 \\
\hline & Aggregate & $q(t)$ & 155 & 101 & 78 & 65 \\
\hline & Median & $\mathrm{Q}(\mathrm{t})$ & 1.3 & 1.7 & 2.1 & 2.3 \\
\hline & Aggregate & $q(t)$ & 227 & 160 & 131 & 113 \\
\hline & Median & $Q(t)$ & 1.6 & 2.2 & 2.8 & 3.2 \\
\hline \multirow{4}{*}{$\begin{array}{l}\text { S } \\
\text { E }\end{array}$} & Mean & $q(t)$ & 140 & 70 & 45 & 32 \\
\hline & Aggregate & $Q(t)$ & 1.4 & 1.7 & 1.9 & 2.1 \\
\hline & Median & $q(t)$ & 196 & 120 & 88 & 70 \\
\hline & Aggregate & $\mathrm{Q}(\mathrm{t})$ & 1.5 & 2.1 & 2.4 & 2.7 \\
\hline
\end{tabular}

If the cut-off rate of production $\left(q_{c o r}\right.$, technical and economic limits, as shown in Figure 2) for a shale gas well can be defined, the expected $Q(t)$ at the time of the cut-off rate $\left(t_{c o r}\right)$ can be used to estimate URR. According to Kaiser [34], who studied the economic limits of oil/gas field production in Texas between 1993 and 2008, the last annual average production in all land wells was $215 \mathrm{Mcf} / \mathrm{d}$. However, condensate was included in the gas stream in that study. Correcting for this, the cut-off rate for natural gas production will likely be less. Browning [35] found that the economic limit for closing a well is $50 \mathrm{Mcf} / \mathrm{d}$ for dry gas in Barnett. Based on the average of those studies, a cut-off production rate at $133 \mathrm{Mcf} / \mathrm{d}$ was assumed, and yields estimated URR and well life time as shown in Table 5 . Results for 215 and $50 \mathrm{Mcf} / \mathrm{d}$ are also shown in Table 5 as reference.

Table 5 URR and well life time per well using a cut-off rate. Unit for URR is Bcf, and for well life time is year.

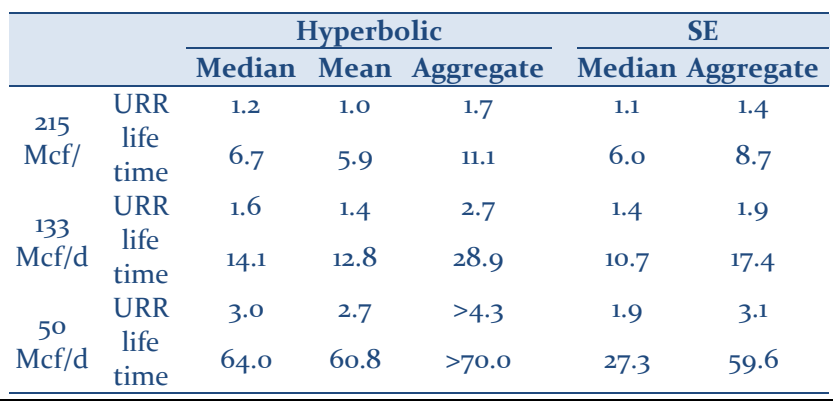


Table 6 present a summary of the estimated URR from other studies of the Barnett shale play for comparison. The results from this study are in line with the EIA and other agencies. Among them, the NETL/DOE study seems to be the most optimistic, and the USGS more pessimistic.

Table 6 Summary of average estimated URR per well in Barnett of other studies. Unit is Bcf.

\begin{tabular}{lccc}
\hline \multicolumn{1}{c}{ Reference } & URR & Method & Time \\
\hline U.S. EIA [36] & 1.4 & Decline curve analysis & 2011 \\
E. Berman [37] & 1.3 & Two-stage exponential decline & 2011 \\
USGS [38] & 1.0 & Decline curve analysis & 2012 \\
NETL/DOE [39] & 3.0 & N/A & 2012 \\
Ruud Weijermars [40] & 1.41 & Well roll-out scenarios model & 2014 \\
This study & & Decline curve analysis & \\
(133 Mcf/d as cut-off ) & $1.4-2.7$ & & \\
\hline
\end{tabular}

\subsection{Discussion of data}

As one of the oldest shale plays in commercial exploitation, the Barnett shale has a relatively long time series as well as abundant well and production data. This study indicates that most of the shale gas wells in Barnett have a typical production pattern of peaking in a short time frame and declining steeply after the peak is reached, while only few wells do not show this characteristic performance.

Twice "bad" wells were removed for curve fitting according to the limits of data series length and goodness of fit. It is assumed in this study that only wells with production exceeding 24 months can show an unbroken production pattern (the first wells eliminated) and that only wells with good fit in line with $\mathrm{R}_{2} \geqslant 0.8$ and $\mathrm{N}-\mathrm{RMSE} \leqslant 0.2$ can on behalf of a characteristic production pattern (the second set of wells removed). Table 7 shows the change of the count and share of wells starting from different years during analysis.

Table 7 The number of yearly new wells used in study and the share of original data.

\begin{tabular}{cccccc}
\hline & Original & Length & Share(1) & Good fit & Share(2) \\
\hline 2000 & 8 & 7 & $88 \%$ & 5 & $63 \%$ \\
2001 & 21 & 21 & $100 \%$ & 14 & $67 \%$ \\
2002 & 52 & 50 & $96 \%$ & 30 & $58 \%$ \\
2003 & 208 & 195 & $94 \%$ & 128 & $62 \%$ \\
2004 & 392 & 369 & $94 \%$ & 272 & $69 \%$ \\
2005 & 762 & 711 & $93 \%$ & 531 & $70 \%$ \\
2006 & 1257 & 1158 & $92 \%$ & 836 & $67 \%$ \\
2007 & 2155 & 2013 & $93 \%$ & 1421 & $66 \%$ \\
2008 & 3672 & 3393 & $92 \%$ & 2354 & $64 \%$ \\
2009 & 626 & 600 & $96 \%$ & 413 & $66 \%$ \\
2010 & 1638 & 1546 & $94 \%$ & 1090 & $67 \%$ \\
2011 & 1415 & 1308 & $92 \%$ & 854 & $60 \%$ \\
2012 & 1120 & 840 & $75 \%$ & 599 & $53 \%$ \\
2013 & 839 & 0 & $0 \%$ & 0 & $0 \%$ \\
2014 & 288 & 0 & $0 \%$ & 0 & $0 \%$ \\
Total & 14453 & 12211 & $84 \%$ & 8547 & $59 \%$ \\
\hline
\end{tabular}

As shown in Table 7 , about $59 \%$ of the original wells data are used to fit typical decline curves for shale gas production. Each year, from 2000 to 2012, display a similar percentage with the largest standing at $70 \%$ in 2005 , and the lowest, 53\%, in 2012. Wells starting in December 2012, 2013 and 2014 are excluded, because those wells will not have produce for 24 months by October 2014 - the end date of the data set.

\section{Conclusions}

This paper derived the characteristics of the decline patterns for shale gas production by analyzing historical well production data using decline curve analysis of 14,453 shale gas wells in the Barnett shale play from 2000 to 2014 . The Hyperbolic model and the Stretched Exponential model were applied on the well-by-well production data at average aggregate well and individual well levels to derive the characteristic parameters.

The study found that most of the investigated shale gas wells in the Barnett shale play have a characteristic production pattern characterized by quickly reaching a peak production followed by steep declines and long-term low production levels. As shown in the results section, when the first year after IP, around $60 \%$ of the production level has been lost due to decline, and after 2 years the production level is only about $25 \%$ of IP (Table 3 ). These high decline rates of shale gas wells, which are in agreement with earlier studies [36-40], are far higher than that of conventional natural gas. To maintain gas-field production level or to increase production, therefore, a large number of "new wells" are annually needed to offset the production decline trend from the "old wells", which will require new investments and drilling sites. Analysis of profit and loss balance based on the characteristic shale gas production pattern are essential before developing the shale play. Furthermore, about $77 \%$ of wells reached the peak production from 20,000 to 100,00o Mcf per month (Figure 9(a)); and there is an increasing trend in IP (Figure 9(b)) that most likely reflects technological gains. That means, raising outputs significantly from a shale gas wells by enhancing recovery efficiency technology is also an efficient way to counteract its high decline rate.

According to the results of goodness-of-fit $\left(\mathrm{R}^{2}\right.$ and NRMSE), both the Hyperbolic curve and the Stretched Exponential curve fit well both to aggregate and individual shale gas wells. The Hyperbolic model, counterintuitively, is slightly better than the Stretched Exponential model in terms of goodness of fit in this study, even where about $84 \%$ of $\beta$-parameter values of the Hyperbolic were larger than 1 . On average, shale gas wells were estimated to yield an ultimate production of 1.4-3.2 Bcf based on the resulting parameters of the applied models (Table 4). However, the highest numbers imply very long well life spans (>20 years). If a cut-off production rate is used, which was supposed to be $133 \mathrm{Mcf} / \mathrm{d}$ in this study, the URR estimate becomes more reasonable and ends up between 1.4-2.7 Bcf (Table 5), and the well life time ranges from 11 to 29 years. The results are in line with other studies (Table 6). As discussed in the Methodology, the traditional Arps model was supposed to 
be used only for describing and predicting in conventional oil and gas wells. While this study indicates that it is still effective for a shale gas well if the economic aspects, such as the cut-off-rate for continued commercial production, is set reasonably. More and deeper analysis on this topic are still needed to be able to estimate the future production and resources.

Under the current situation on the preliminary stage of shale development globally, lack of complete production data is one of the most imminent obstacles of deep researches for shale oil and gas production patterns. Even though the geological conditions vary from shale plays, the production pattern of shale gas wells has general characteristics. The conclusions of this study can provide more detailed knowledge of shale gas production for the analysts and policymakers. The parameters of the models analyzed in the study can be adjusted to describe and predict shale gas production beyond the Barnett shale play, as well as beyond North America.

\section{Acknowledgements}

The authors would like to thank DrillingInfo for providing access to their extensive database, without which this study would have been difficult to accomplish. The authors also would like to give many thanks to the National Social Science Foundation of China (Grant No. 13\&ZD159) for sponsoring this research. This study has been supported by the StandUp for Energy collaboration initiative.

We would also like to thank Simon Snowden for proofreading and helpful comments.

\section{References}

[1] McGlade, C.; Speirs, J.; Sorrell, S. Unconventional gas - A review of regional and global resource estimates. Energy 2013, 55, 571-584.

[2] Tian, L.; Wang, Z.; Krupnick, A.; Liu, X. Stimulating shale gas development in China: A comparison with the US experience. Energy Policy 2014, 75, 109-116.

[3] Jia, C.; Zheng, M.; Zhang, Y. Unconventional hydrocarbon resources in China and the prospect of exploration and development. Petroleum Exploration and Development 2012, 39, 139-146.

[4] Misiak, U. B.; Przybycin, A.; Winid, B. Shale and tight gas in Poland-legal and environmental issues. Energy Policy 2014, 65, 68-77.

[5] Maya, J. R. L. The United States experience as a reference of success for shale gas development: The case of Mexico. Energy Policy 2013, 62, 70-78.

[6] Shah, S.; Totlani, K. Difficulties and prospects of Coalbed methane in India as compared to North America. Journal of Unconventional Oil and Gas Resources 2014, 6, 48-53.

[7] Trigger, D.; Keenan, J.; Rijke, K.; Rifkin, W. Aboriginal engagement and agreement-making with a rapidly developing resource industry: Coal seam gas development in Australia. The Extractive Industries and Society 2014, 1, 176-188.

[8] Hu, D.; Xu, S. Opportunity, challenges and policy choices for China on the development of shale gas. Energy Policy 2013, 6o, 21-26.
[9] Kewen, L.; Roland, N. H. A Decline Curve Analysis Model Based on Fluid Flow Mechanisms. SPE Reservoir Evaluation $\mathcal{E}$ Engineering 2005, 8, 197-204.

[10] U.S. Energy Information Administration (EIA). Annual Energy Outlook 2015. Washington, DC 20585, DOE/EIA-0383(2015), Apr. 2015.

[11] U.S. Energy Information Administration (EIA). Technically Recoverable Shale Oil and Shale Gas Resources: An Assessment of 137 Shale Formations in 41 Countries Outside the United States. Washington, DC 20585, Jun. 2013.

[12] U.S. Energy Information Administration (EIA). North America leads the world in production of shale gas. Available online: http://www.eia.gov/todayinenergy/detail.cfm?id=13491 (accessed on 23 Oct 2013).

[13] Ralroad Commission of Texas. Barnett Shale Information: Major Oil \& Gas Formations. Available Online: http://www.rrc.state.tx.us/oil-gas/major-oil-gasformations/barnett-shale-information/ (accessed on 1 Jun 2015).

[14] StateImpact Texas. What Is The Barnett Shale?. Available Online: https://stateimpact.npr.org/texas/tag/barnett-shale/ (accessed on 5 Jun 2015).

[15] Khanamiri, H. H. A non-iterative method of decline curve analysis. Journal of Petroleum Science and Engineering 2010, 73, 59-66.

[16] Arps, J. J. Analysis of Decline Curves. Transactions of the AIME 1945, 160, 228 - 247.

[17] Satter, A.; Lqbal, G. M.; and Buchwalter, J. L. Practical Enhanced Reservoir Engineering - Assisted with Simulation Software. Tulsa, OK: Penn Well Corp., 2008.

[18] Höök, M. Depletion rate analysis of fields and regions: A methodological foundation. Fuel 2014, 121, 95-108.

[19] Doublet, L. E.; Pande, P. K.; McCollum, T. J.; Blasingame, T. A. Decline Curve Analysis Using Type Curves-Analysis of Oil Well Production Data Using Material Balance Time: Application to Field Cases. In Proceedings of International Petroleum Conference and Exhibition of Mexico, Veracruz, Mexico, 10-13 October, 1994. DOI: http://dx.doi.org/10.2118/28688-MS.

[20]Höök, M.; Hirschb, R.; Aleklett K. Giant oil field decline rates and their influence on world oil production. Energy Policy 2009, 37, 2262-2272.

[21] Höök, M.; Söderbergh, B.; Aleklett K. Future Danish oil and gas export. Energy 2009, 34, 1826-1834.

[22] Sorrell, S.; Speirs, J.; Bentley, R.; Miller, R.; Thompson E. Shaping the global oil peak: A review of the evidence on field sizes, reserve growth, decline rates and depletion rates. Energy 2012, 37, 709-724.

[23] Xu, X.; Gong, J. A united model for predicting pressure wave speeds in oil and gas two-phase pipeflows. Journal of Petroleum Science and Engineering 2008, 60, 150-16o.

[24] Ilk, D.; Rushing, J. A.; Albert, D. P.; Blasingame, T. A. Exponential vs. Hyperbolic Decline in Tight Gas Sands: Understanding the Origin and Implications for Reserve Estimates Using Arps' Decline Curves. In Proceedings of the SPE Annual Technical Conference and Exhibitio, Denver, Colorado, USA, 2008.

[25] Valko, P. P. Assigning value to stimulation in the Barnett Shale: a simultaneous analysis of 7000 plus production hystories and well completion records. In Proceedings of the SPE Hydraulic Fracturing Technology Conference, The Woodlands, Texas, 2009.

[26] Valko, P. P; Lee, W. J. A Better Way To Forecast Production From Unconventional Gas Wells. In Proceedings of SPE Annual 
Technical Conference and Exhibition, Florence, Italy. 19-22 September, 2010. DOI: http://dx.doi.org/10.2118/134231-MS.

[27] Duong, A. N. Rate-Decline Analysis for Fracture-Dominated Shale Reservoirs. SPE Reservoir Evaluation E Engineering 2011, 14, 377-387.

[28] Höök, M.; Davidsson, S.; Johansson, S.; Tang, X. Decline and depletion rates of oil production: a comprehensive investigation. Philosophical Transactions of the Royal Society of London A: Mathematical, Physical and Engineering Sciences 2014, 372, no. 2006, p. 20120448.

[29] Kanfar, M.; Wattenbarger, R. Comparison of Empirical Decline Curve Methods for Shale Wells. Proceedings of the SPE Canadian Unconventional Resources Conference, Calgary, Alberta, Canada, 2012.

[30]Lei, D.; Wang, L.; Zhang, X.; and Wang, N. Stretched exponential decline model for shale gas well. Fault-Block OilEGas Field 2014, 1, 66-68.

[31] DrillingInfo database. Available Online: http://info.drillinginfo.com/ (accessed on 30 Aug 2016)

[32] Wang, J.; Feng, L.; Zhao L.; Snowden, S.; Wang, X. A comparison of two typical multicyclic models used to forecast the world's conventional oil production. Energy Policy 2011, 39, 7616-7621.

[33] Patzek, T. W.; Croft G. D. A global coal production forecast with multi-Hubbert cycle analysis. Energy 2010, 35, 3109-3122.

[34] Kaiser, M. J.; Yu, Y. Economic limit of field production in Texas. Applied Energy 2010, 87, 3235-3254.

[35] Browning, J.; Tinker, S. W.; Ikonnikova, S. BARNETT SHALE MODEL-2 (Conclusion): Barnett study determines full-field reserves, production forecast. OILEGAS JOURNAL 2013. Available Online: http://www.ogj.com/articles/print/volume111/issue-9/drilling-production/barnett-study-determines-fullfield-reserves.html (accessed on 02 Sep 2013).

[36] U.S. Energy Information Administration (EIA). Review of Emerging Resources: U.S. Shale Gas and Shale Oil Plays. U.S. Department of Energy, Washington, DC 20585, Jul. 2011.

[37] Berman, A. E.; Pittinger, L. F. The Oil Drum - U.S. Shale Gas: Less Abundance, Higher Cost. Available Online: http://www.theoildrum.com/node/8212 (accessed on 05 Aug 2011).

[38] U.S. Geological Survey Oil and Gas Assessment Team. Variability of Distributions of Well-Scale Estimated Ultimate Recovery for Continuous (Unconventional) Oil and Gas Resources in the United States. 2012-1118, Jun. 2012.

[39] Skone, T. J. Role of Alternative Energy Sources: Natural Gas Technology Assessment. NETL/DOE-2012/1539, Jun. 2012.

[40]Weijermars, R. US shale gas production outlook based on well roll-out rate scenarios. Applied Energy 2014, 124, 283-297.

\section{Appendix A. Probability density functions}

A. 1 Generalized Logistic Distribution

$$
f(x)=\left\{\begin{array}{c}
\frac{(1+k z)^{-1-1 / k}}{\sigma\left[1+(1+k z)^{-1 / k}\right]^{2}}, k \neq 0 \\
\frac{\exp (-z)}{\sigma[1+\exp (-z)]^{2}}, k=0
\end{array}\right.
$$

\section{A. 2 Normal Distribution}

$f(x)=\frac{\exp \left[-\frac{1}{2}\left(\frac{x-\mu}{\sigma}\right)^{2}\right]}{\sigma \sqrt{2 \pi}}$

A. 3 Log-Pearson 3 Distribution

$f(x)=\frac{1}{x|b| \Gamma(a)}\left(\frac{\ln (x)-c}{b}\right)^{a-1} \exp \left(-\frac{\ln (x)-c}{b}\right)$ 